\title{
Worker Cooperatives and their Entrepreneurial Process. Theoretical Foundations and Empirical Evidence from the Worker Cooperatives Established in the Valencian Community, 2008-2014
}

\author{
Manuel Monreal Garrido \\ manuel.monreal@uv.es \\ Juan José Renau Piqueras Department of Business Administration \\ Instituto Universitario de Investigación en Economía Social (IUDESCOOP) \\ Universidad de Valencia, Spain
}

\begin{abstract}
The context of worker cooperatives is significantly different from that of traditional firms, and so the study of entrepreneurship also differs considerably. The analysis of the creation of worker cooperatives requires differentiated approaches, as the more conventional models of entrepreneurship do not prove adequate to this end. We analyze certain determinants of the entrepreneurial process from a sociocultural perspective, which is applicable specifically to this type of firm.

Based on the most important proposals of the network, business incubation, role, and marginalization theories from the sociocultural and institutional standpoints, we establish causal links between the determinants of the start-up process and the outcomes expected by cooperative entrepreneurs, in terms of both the performance of the firm itself and the personal outcomes anticipated by these entrepreneurs.

From a sample of 103 firms out of a total of 633 cooperatives set up in the Valencian Community (Spain) over the period 2008-2014, and by way of a quantitative methodology drawing on structural equations - and specifically, SmartPLS - we analyze the influence of the determinants on the outcomes of entrepreneurship; in so doing, we aim to establish both the influence or the direct effects on these outcomes and the indirect or mediation effects of the respective outcome variables, as well the possible moderation effects that may be exercised between the independent factors.
\end{abstract}

Keywords: Cooperative entrepreneurship, worker cooperatives, causal relationships, business performance, incentives, structural equations. 
Monreal Garrido, M. (2018) Worker Cooperatives and their Entrepreneurial Process. Theoretical Foundations and Empirical Evidence from the Worker Cooperatives Established in the Valencian Community, 2008-2014. Journal of Business, Universidad del Pacifico (Lima, Peru) Vol.10(1): 2-23

\section{Introduction}

The worker cooperative,$^{1}$ just like the traditional capitalist firm, pertains to the so-called team production model, even if from an organizational point of view it has significant differences in terms of the decision-making system, the expected behavior of its members, the incentives, and the labor relations.

The decision-making system is determined by the contractual structure; unlike the traditional capitalist firm in which ownership and control are clearly separated, the worker cooperative makes no such distinction and all workers have the same ownership rights, resulting in equal relations (Orellana, 2002).

Moreover, members' behavior will respond preferentially to survival value incentives, more closely related to the objectives and growth of the firm within a context of broadbased responsibility and discretion in their actions. All this is a product of the participation of the members in running the firm, either directly or through representative bodies.

As to labor-contractual relations, relational team governance structures predominate (Williamson ,1985) with a preponderance of idiosyncratic workers in a context of participative and communicative labor, in that the shared information and experience, the relationships of trust, and the convergence between individual interests and the objectives of the cooperative lend the worker idiosyncratic characteristics that are hard to find on the labor market.

Therefore, the decision-making system, members' behavior, and labor relations in a worker cooperative give rise to a distinctive and singular organizational context that has repercussions for the development and consolidation stages of the entrepreneurial process, and especially for the entrepreneurial outcomes. In this study, after presenting the conceptual framework and the particular entrepreneurial conditions to which organizations of this type are subject, we seek to contribute by analyzing how certain determinants in the creation of cooperatives affect their entrepreneurial outcomes, which we group into two components: on the one hand, the material outcomes of the firm's performance, which affects the firm itself; and on the other, the level of fulfillment of personal expectations, or the personal outcomes of the entrepreneurs.

We conducted this study using a representative sample of 103 cooperatives, out of a total of 633 established in the Valencian Community (Spain) from 2008 to 2014: a period marked by the start of the recent economic crisis, the peak years of that crisis, and the start of the recovery. While the economic crisis is not the principal motive for this work, it has served to foreground the idiosyncratic capacities and characteristics of the cooperative entrepreneurs in their efforts to survive and confront it.

We have opted for a quantitative analysis based on structural equations, since the literature on cooperative entrepreneurship contains few studies of this type yet there have been sufficient qualitative works, some of them drawing on theories from the sociocultural approach, which is what we ultimately follow here.

\footnotetext{
1 In Spain, the legal denomination is cooperativa de trabajo asociado, often referred to in the Spanishlanguage literature by the initials CTA, but here for simplicity we use the standard English translation of "worker cooperative."
} 
Monreal Garrido, M. (2018) Worker Cooperatives and their Entrepreneurial Process. Theoretical Foundations and Empirical Evidence from the Worker Cooperatives Established in the Valencian Community, 2008-2014. Journal of Business, Universidad del Pacifico (Lima, Peru) Vol.10(1): 2-23

\section{Towards a Conceptual Framework for Entrepreneurship}

\section{Determinants for the study of worker cooperatives}

It is an established fact that the creation of worker cooperatives does not correspond exactly to the canons of entrepreneurship followed by traditional capitalist firms, which, when it comes to the study of the former, makes it difficult to fit them to the most widespread general models on entrepreneurship. This implies that the cooperative formation process ought to be studied from a different perspective than the patterns of general entrepreneurship utilized thus far, in which the financial perspective in the measurement of business success is what tends to orient all related topics.

Moreover, and in practice, the study of worker cooperatives has been dominated by the general research program on business and entrepreneurship, which is founded on traditional capitalist enterprise, without taking into account that cooperatives and their entrepreneurial process might be best considered a "new phenomenon." This has hampered the development of a robust conceptual framework with which to drive the study of cooperative entrepreneurship and reveal the potential it holds as an organizational form.

Thus, we propose some ideas for approaching the study of the process of entrepreneurship in worker cooperatives as a new phenomenon, or at least as a singular phenomenon within the study of business organization. The fundamental differences that cooperative entrepreneurship exhibits in comparison to its traditional counterpart can be illustrated by way of a brief analysis of the factors that determine entrepreneurship as proposed by Wickham (2004), and how these contrast with the cooperative form.

For Wickham, these factors are: (i) an individual; (ii) a market opportunity; (iii) adequate resources; (iv) a business organization; and (v) a favorable environment. Wickham considers these factors to be contingencies; that is, they are present in entrepreneurship, but can manifest themselves in different ways. And it is by setting these factors against cooperative entrepreneurship that we can discern significant differences.

Indeed, the second factor, "A market opportunity," is not always applicable, because cooperative entrepreneurs do not generally follow this line. The same can be said of the third factor, "adequate resources," given that cooperatives are typically characterized by their resource constraints. But the difference is starker still in the case of the fifth factor, "a favorable environment," in the sense intended by Wickham. This bears no relation to cooperative entrepreneurship, as studies stretching back more than a decade (Vienney, 1991; Díaz-Bretones, 2000, 2000b), as well as more recent contributions (Salinas \& Osorio, 2012; Díaz-Foncea \& Marcuello, 2015), show that the main determinant in their creation is the level of unemployment.

Indeed, there is correspondence only with the first factor, "an individual" in Wickham's formulation, even though cooperatives are collective endeavors; and with the fourth factor, "A business organization."

As part of our research, and following a review of the most-cited proposals in the scientific literature on entrepreneurship, we have developed a conceptual framework for worker 
cooperative entrepreneurship based on the most innovative concepts proposed, as befits an organizational form with its own characteristics: a hybrid between firm and clan.

Outstanding contributions include those of Álvarez \& Barney (2005); Rindova, Barrey \& Ketchen (2009); Morris, et al., 2001; and Kuratko et al. (2015). Thus, and in this regard, the different forms of cooperative entrepreneurship are most closely aligned to the conceptualization of Rindova, Barrey \& Ketchen (2009), for whom it a form of emancipation, a type of entrepreneurship practiced in contexts not traditionally considered part of the domain of business initiative, in the same vein as explorers, scientists, artists, freelancers, and other social entrepreneurs in the sense of Rothschild (2009). Along these lines, the work of Morris et al. (2001), subsequently expanded in a recent article by Kuratko et al. (2015), develops various approaches to entrepreneurship, and integrates them into what they call a "framework of frameworks" that encompasses each of the variables which condition entrepreneurial activity (Figure 1).

At the center of this "supra-framework" lies the process of entrepreneurship, understood as the process of creating value by bringing together the available resources to exploit an opportunity. This process is initiated by an entrepreneur (Stevenson, et al., 1992; Shane \& Venkataraman, 2000), a role that can even be played by individuals who did not conceive of the idea or concept (although it is they who persevere in its adaption and application, and who contribute in certain measure to success or failure); moreover, since there is no genetic characteristic or predisposition to become one, many people can be potential entrepreneurs.

Figure 1: An integrated framework for entrepreneurship

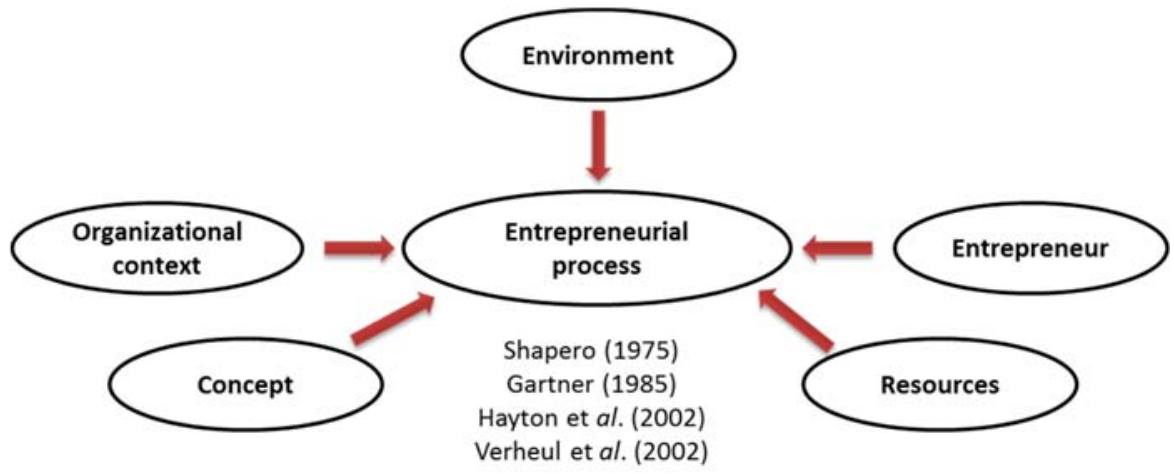

Source: adapted from Morris et al. (2001)

Álvarez \& Barney (2005) make an interesting contribution from the sphere of organizational economics, proposing that entrepreneurial activity amasses and coordinates resources through the creation of an organization, and on this basis two critical decisions must be made: a) who will run the organization (the location of decisionmaking); and b) how the claims on the residual cash flows are to be distributed. Since the entrepreneur has to make these decisions without knowing what the outcomes of the activity will be - that is, under conditions of uncertainty - the organizational form ultimately adopted must respond to the degree of uncertainty perceived by the entrepreneur. And in cases of uncertainty, it is clan-based entrepreneurial firms that will 
be adopted (following Ouchi, 1980), characterized by the sharing of residual and decision-making rights among their members. Accordingly, those who form part of such firms believe that the sharing of both rights is essential for creating value and building trust within the organization. This will have the following repercussions: a) the fundamental decisions will be based on the opinion of the essential employees; and $b$ ) profits will be distributed according to the contribution of each employee (Álvarez \& Barney, 2005: 783). The ideas provided by previous works can be summarized as follows:

1. Entrepreneurship in contexts not traditionally considered part of the domain of business initiative;

2. The entrepreneur as executor of an entrepreneurial process;

3. The clan-type organization as barrier to uncertainty; and

4. Entrepreneurship as emancipation.

These ideas are vital to the selection of explanatory variables and factors for the firm creation process in some of the established general models of entrepreneurship, such as those of Shapero (1975), Shapero \& Sokol (1982), Gartner (1985), Hayton et al. (2002), and Verheul et al. (2002), among others. All of these models have a multidimensional character in common, incorporating all kinds of variables and factors ranging from the economic, the sociocultural, and the psycho-sociological to the institutional, with a clear predominance of environmental factors.

However, if entrepreneurship in contexts removed from the traditional - such as worker cooperatives - is not explicitly factored into these models, it is therefore justifiable to steer the study of cooperative entrepreneurship towards an institutional and sociocultural approach. Indeed, the variables and factors that affect the process of creating worker cooperatives, and which we will go on to analyze here, are closely related to this approach.

\section{Sociocultural Factors in the Entrepreneurial Process of Worker Cooperatives}

The theories observed in the sociocultural approach hold that the formation of new firms - in this case, worker cooperatives - has its origins in external factors, whereby it is the sociocultural factors and the institutional framework that can prove more or less favorable for the creation of new businesses or the decision to become an entrepreneur, and perceptions about the environment are a crucial component of an individual's decisionmaking to this end. The most representative theories in this approach, besides institutional theory itself, are marginalization theory, role theory, network theory, and business incubation theory. ${ }^{2}$

Institutional theory provides a highly consistent and appropriate framework with which to study the influence of environmental factors on entrepreneurship and on business creation. It distinguishes between formal (political, legal, economic, and contractual norms) and informal factors.

The formal factors are those that define the framework for action, the patterns of behavior, and the degree of discretion in the actions. ${ }^{3}$ In turn, the informal factors act as

\footnotetext{
2 The chief contributions to the field of role, network, and business incubation theory include those of Cooper (1985), and Cooper \& Dunkelberg (1987).

${ }^{3}$ Williamson (1985) in the field of organizational economics and North (1990) in the field of economic theory are the leading authors in the study of institutional factors as economic determinants.
} 
a kind of backdrop, in that many of the actions of the economic agents are guided by informal factors, related as they are to aspects that are more cultural and social.

In turn, according to marginalization theory, the creation of a firm begins with a discontinuity or negative displacement (Shapero, 1975) or a critical happening, generally negative, which precipitates the process in which what is known as role deterioration Collins et al., 1964) or a trigger event (Shapero, 1982) occurs, where the most inclined or prone to become entrepreneurs, as the theory has it, are those who are unadapted or marginalized. As such, the results of studies such as those of Evans \& Leighton (1989) and Bathes (1997) have shown that the decision to start a business is motivated by a negative event, which generally unleashes and/or precipitates the business creation process. In this theory, and as Brunet \& Alarcón (2004) assert, there are two requirements for becoming an entrepreneur: a) a period of maturation of the idea starting from an earlier point; and b) an event that triggers the creation, which does not necessarily correspond to the rationale of exploiting an opportunity or obtaining a benefit but rather is provoked by a negative critical event, such as prolonged unemployment, dismissal, a lack of job security, or simply dissonance with the ideas and objectives of the firm that provides one with work, prompting abandonment thereof (Tervo, 2006). In this latter case, when a firm breaks the promises and expectations that it has made to or created in an employee, that individual will be divested of their desire to continue working for that firm and will opt to start their own business by harnessing their knowledge and skills, instead of looking for another job.

For its part, business incubation theory holds that many ideas that lead to the creation of a new business are related directly to the occupation, experience and knowledge acquired at the firm where the founding partner of the new business previously worked. One strand of this theory analyzes the need to create and develop businesses, which has prompted public administrations, universities, chambers of commerce and even some non-governmental organizations to establish and develop incubator programs (OCDE, 1999). Business incubators assist future entrepreneurs in starting up their businesses, furnishing them with basic infrastructure, recourses, and various kinds of services and information for their endeavors. The new businesses that result from this process are called spin-offs. However, most research on business incubators analyze the relationship or connection between the firm where the entrepreneur previously worked and the new business that individual has created, judging the former to have acted as incubator for the new venture since it is the environment in which the entrepreneur discovered and applied a business idea (Westhead \& Wright, 1998).

Meanwhile, role theory seeks to explain, among other things, why more businesses are created in some geographical areas than in others, showing that start-ups are found in larger numbers in industrial regions with an "entrepreneurial tradition, or at the very least, an industrial fabric. The existence of entrepreneurial models to replicate in a given geographical environment creates a ripple effect that stimulates or induces the emergence of new entrepreneurs Nueno, 1996). That is, it is a situation in which a future entrepreneur notes that other individuals have succeeded in creating their own businesses in similar circumstances, and so decides to follow suit (Veciana, 1996). If, on the other hand, the environment offers the entrepreneur the prospect of assessing others effectively and of achieving a certain social prestige, this will amount to more favorable conditions for business creation. This theory, as well as considering external factors, takes into account other internal factors more closely related, for instance, to the influence of the environment or the family where entrepreneurial roles or a greater predisposition to start businesses have been in evidence. This can condition the inclination of offspring and other family members towards entrepreneurial ventures more than other professions, serving as a source of assistance, stimulation, and support, both social and economic. 
Finally, network theory attempts to explain the role of social networks in the business startup process, stressing that networks are vital to identifying opportunities and obtaining the necessary resources and thus are critical elements for emerging organizations. This theory acquired importance in the 1980s, opening up an avenue of research into the impact of the network in the business creation process. However, despite an extensive literature relating social networks to business creation, few studies yet have explored the existence and structure of formal business networks and their true implications for the process of entrepreneurial development (Minniti, 2005).

Network theory proposes that the set of specific relationships between several groups or actors provides multiple interconnections and chain reactions, which results in the circulation of information and ideas and facilitates business creation (Alonso \& Galve, 2008). In the consideration of different authors, there is a great variety of network types. Birley (1985), distinguishes between formal (banks, professionals, chambers of commerce) and informal networks (families, friends, workmates), arguing that new entrepreneurs avail more of the latter than the former.

Having briefly introduced the most representative theories in the sociocultural and institutional approach, in Table 1 we present the determinants of entrepreneurship in worker cooperatives and how they relate to these theories.

Table 1: Determinants of the entrepreneurial process and related theories

\begin{tabular}{l|c}
\hline \multicolumn{1}{c|}{ Determinant of the entrepreneurial process } & Related theory \\
\hline CAUSENTR: Causes of entrepreneurship & Marginalization theory \\
\hline FAMCONT: Family context & Role theory \\
\hline PRIOREXP: Prior experience & Business incubation theory \\
\hline $\begin{array}{l}\text { RELAGENV: Relationships with agents in the } \\
\text { environment }\end{array}$ & Network theory \\
\hline
\end{tabular}

Source: compiled by author

\section{Variables and Constructs. Relationship and Hypotheses}

We will incorporate the above-mentioned determining factors of the firm creation process in our structural model as constructs or latent factors, constituting the independent or explanatory variables. They will have an influence on or a causal relationship with the outcomes of cooperative entrepreneurship, and these outcomes will be considered as endogenous or dependent variables on which the determinant factors have an influence. As stated, the determinants constitute two categories of constructs, or latent factors, it having been established that the entrepreneur outcomes of the entrepreneurs are of a different nature: a) the material outcomes of the firm's performance; and b) the level of fulfillment of the entrepreneur's personal expectations, which we call personal outcomes.

\section{Causes for Entrepreneurship (CAUSENTR)}

Captures the possible causes for initiating entrepreneurship, as an environmental push factor compelling an individual to start a business, per marginalization theory and some aspects of business incubation theory (Orellana \& Martínez de Lejarza, 2013). The following are considered causes for entrepreneurship, whose measurement scale is 
established as a formative construct. For the measurement, we have determined the percentage, out of the total members, of each possible origin or cause for entrepreneurship in each cooperative studied.

- X11: Individuals in their first job after finishing their education

- X12: Frictional unemployment or self-employed

- X13: Long-term unemployment and/or social exclusion

- X14: Crisis in previous capitalist firm

- X15: Crisis in previous cooperative

\section{Family Context (FAMCONT)}

Based on role theory, family context corresponds to a broad concept that captures all kinds of influences and situations in the family environment in relation to entrepreneurial action. For this construct, we have established four reflective indicators in order to analyze their impact on the following outcome factors.

- X21: Family history of entrepreneurship

- X22: Assistance received from family members

- X23: Active influence from the family to engage in entrepreneurship

- X24: Family relations with cooperatives

\section{Prior Experience (PRIOREXP)}

This latent factor, from the perspective of business incubator theory, captures the prior relationship of entrepreneurs with firms, and the knowledge supposedly acquired from previous jobs, making reference both to the individual's experience as an employee and the individual's professional experience before making the decision to become an entrepreneur, measured by way of the following indicators.

- X31: General experience.

- X32: skilled technical experience.

- X33: Management and leadership experience.

\section{Relationships with Agents in the Environment (RELAGENV)}

From the perspective of network theory, we propose the construct relationships with agents in the environment to capture the relationships that the firm has succeeded in establishing and developing effectively with these agents as a way of accumulating capacities and intangibles in the form of relational capital, and establish their impact on the outcome factors. We have also selected a set of reflective indicators to measure this factor, which represent relationships with:

- X41: Suppliers (stable and long-term relationships)

- X42: Customers (regular or loyal clientele, not considering sales figures)

- X43: Firms from different sectors

- X44: Other cooperatives

- X45: Advisors and consulting firms

- X46: Professional and business associations

- X47: Public entities in general

\section{Worker Cooperative Entrepreneurial Ventures and Outcomes}


A partner's length of service at the cooperative, partner status, and knowledge of the firm lends their work an idiosyncratic character, in that the values and clan-like sentiment developed therein are not readily transferable to another organization (Ouchi, 1980). Moreover, their incentives have an important qualitative component based more on the values of preservation and survival of the firm. This has important repercussions on the study of worker cooperative entrepreneurship, because it suggests that this process ought to be looked at from a different perspective from the patterns of traditional entrepreneurship followed thus far in which, as we have noted, the financial component in the measurement of success or the business outcome is what generally orients research on related topics.

The outcomes of entrepreneurship, or entrepreneurial outcomes, refer to the level of attainment of the entrepreneur's aspirations across two categories: a) material outcomes associated with the performance of the firm (PERFORM); and $\mathrm{b}$ ) the outcomes stemming from fulfillment of personal expectations (PEROUTC), giving rise to the general hypotheses to be compared in the structural models we establish in this study. We establish hypotheses for the direct relationship or influence of the various determinants of the entrepreneurial process on each of the factors that represent the entrepreneurial outcome. Then in a second analysis, we will go on to verify the possible indirect or mediation relationships, in this case of the performance variable, which acts on the direct relationships of the factors with the other dependent variable personal outcomes. In a final analysis, we will scrutinize the possible moderation effects that a certain independent factor may exercise in its relationship with the outcome variables.

\section{Business Performance (PERFORM)}

An important question is how to measure business performance in a way that adapts to the specificities of worker cooperatives. March \& Yagüe (2009), in consideration of the concepts of firm effect and sector effect, in line with the seminal works of Schmalensee (1985) and Rumelt (1991), conduct an empirical study on worker cooperatives and worker-owned firms in the Valencian Community, obtaining a set of proxy variables ${ }^{4}$ to measure business performance. Their results make no significant distinction between the firm effect and the sector effect, and so they apply common performance-assessment criteria across different firm types with no significant sectoral differences. To measure this reflective construct, they select the following group manifest variables, or indicators, integrated into two axes.

- Y11: Evolution of turnover.

- Y12: Evolution or increase in staff (partners and non-partners)

- Y13: Evolution or increase in investment.

- Y14: Assessment of overall business performance.

- Y15: Assessment of performance over the last year.

- Y16: Assessment of performance in relation to direct competitors.

\footnotetext{
${ }^{4}$ A set made up of 13 variables, integrated into two axes. The first assesses the production system using quantitative information on the consumption of inputs and the productivity obtained. The second groups together variables related to size, trajectory, investment, and business profitability.
} 
The first three indicators establish the evolution, by way of comparison between the situation at the start of activity and at present, of three key business indicators: turnover, level of employment, and investment effort. These indicators are objectives, in that they respond to the comparable quantitative values, while the indicators related to the overall performance assessment, for the last year and in relation to competitors, are estimates or subjective perceptions of the managers, though they remain largely comparable.

\section{Personal Outcomes (PEROUTC)}

Each of the important factors that affect the expectations of entrepreneurs can be grouped into two types of basic mechanisms that act on extrinsic and intrinsic human motivation, also known as intrinsic and extrinsic motivation mechanisms (Orellana \& Monreal, 2007), in close connection to the design of incentives.

Motivation will be extrinsic when an individual's behavior in performing a given task is largely determined by the benefit they hope to obtain, or the loss they seek to avoid, both of which are fundamentally material and, thus, are closely associated with monetary or at least material incentives. Conversely, when the task in itself serves as motivation for the individual - that is, no external inducements are needed to accomplish the task as agreed - the motivation will be intrinsic.

There are multiple ways and situations in which individuals can feel motivated in a firm; for instance, when they are assigned tasks whose completion is rewarding, when they have the chance to take part in decision-making, or when they have a share in the ownership of the company - as in the case of partners-workers in cooperatives.

Three indicators are proposed for measuring intrinsic motivation, which are closely related to working environment, working conditions, and personal expectations.

- Y21: Satisfactory relationships with partners/workmates

- Y22: Job satisfaction.

- Y23: Acceptance of one's ideas by others.

On the other hand, and also in eminently simplified terms, the indicators that measure extrinsic motivation are grouped into two categories, and refer to the degree of fulfillment of expectations from a material perspective, or at least capture the influence of external stimuli.

- Y24: Fulfillment of work expectations

- Y25: Fulfillment of professional and business expectations

\section{Research Methodology, Relationships and Hypotheses}

We study the influence of the determinants of worker cooperative entrepreneurship on the entrepreneurial outcome factors, first analyzing the direct relationships between the independent factors and both dependent factors of the entrepreneurial outcome. Then, we analyze the causal relationships between the independent factors and the factor personal outcomes factor, but this time taking into account indirect relationships; that is, by way of the performance factor, which will play the role of mediator variable in this relationship. In addition, we explore possible interactions in the relationship between 
some of the independent factors and the outcome factors, with a view to identifying moderation effects. Table 2 shows the breakdown of our research corresponding to the group of worker cooperatives established in the Valencian Community over the period 2008 to 2014.

We have modeled the relationships established between the determining factors of the entrepreneurial process and the entrepreneurial outcomes by way of the PLS-SEM structural equations methodology, obtaining standardized- $\beta$ regression coefficients, and their statistical significance, which assesses the importance of the relationship between these factors. We will obtain this significance using Student t-values and the confidence interval technique (Preacher \& Hayes, 2008; Hayes (2009).

We also determine the standardized loading $(\lambda)$ and standardized weights $(\omega)$ of the different indicators or variables identified that measure the constructs, as well as their level of statistical significance. We will obtain the $R^{2}, Q^{2}$ and AVE (average variance extracted) indexes. We will determine the psychometric properties of the models proposed in terms of their individual item reliability, their composite reliability, and their convergent and discriminant reliability, so as to test the hypothesis as appropriate.

Table 2: Research break Down

\begin{tabular}{|c|c|}
\hline $\begin{array}{l}\text { Description of the } \\
\text { universe }\end{array}$ & 633 worker cooperatives created over the period $2008-2014$ \\
\hline $\begin{array}{l}\text { Sample selection } \\
\text { methodology }\end{array}$ & Simple random sample \\
\hline Sample size & $\begin{array}{l}\text { Final contacts for sending the questionnaires: } \mathbf{5 4 6} \text { worker } \\
\text { cooperatives } \\
\text { Responses from } 103 \text { worker cooperatives } \\
\text { Response rate out of: } \\
\text { - Firms contacted (546): } \mathbf{1 8 . 6 5 \%} \\
\text { - Population (633): } \quad \mathbf{1 6 . 2 7 \%}\end{array}$ \\
\hline $\begin{array}{l}\text { Confidence levels and } \\
\text { margin of error in the } \\
\text { results presented }\end{array}$ & $\begin{array}{l}\text { Errors: }{ }^{* * *} p<0.001{ }^{* *} p<0.01{ }^{*} p<0.05 \\
\text { Confidence levels: } 99.9 \%, \quad 99 \% \text { and } 95 \%\end{array}$ \\
\hline $\begin{array}{l}\text { Techniques applied to } \\
\text { carry out the fieldwork }\end{array}$ & $\begin{array}{l}\text { Quantitative: questionnaires completed by the worker } \\
\text { cooperatives }\end{array}$ \\
\hline $\begin{array}{l}\text { Information collection } \\
\text { period }\end{array}$ & December 2014 to June 2015 \\
\hline
\end{tabular}

Source: compiled by author

The structural model captures the direct causal relationships between each of the predictor constructs - which represent the determinants in firm creation - with the dependent factors of entrepreneurial outcome, performance (PERFORM) and personal outcomes (PEROUTC); as well as the indirect relationships of each independent factor with the personal outcomes, in which the variable performance now plays a mediation role. Then, we verify the possible interactions or moderation effects between the independent factors or predictors in their relationship with the entrepreneurial outcome factors, and perform an analysis of the results. 
Monreal Garrido, M. (2018) Worker Cooperatives and their Entrepreneurial Process. Theoretical Foundations and Empirical Evidence from the Worker Cooperatives Established in the Valencian Community, 2008-2014. Journal of Business, Universidad del Pacífico (Lima, Peru) Vol.10(1): 2-23

Figure 2 represents the structural model that captures the direct relationships between independent factors and the entrepreneurial outcome factors, as well as the mediation relationship described by the factor performance of the firm, based on the following hypotheses:

Hypothesis $H_{.1}$ a: the factor causes for entrepreneurship (CAUSENTR) has a direct influence on the factor personal outcomes (PEROUTC). Hypothesis H.1 b: The factor causes for entrepreneurship (CAUSENTR) has a direct influence on the factor performance of the firm (PERFORM), and an indirect influence on personal outcomes (PEROUTC), by way of performance (PERFORM). Hypothesis $H_{2}$ a: the factor family context (FAMCONT) has a direct influence on the factor personal outcomes

(PEROUTC). Hypothesis $H_{2} b$ : The factor family context (FAMCONT has a direct influence on the factor performance of the firm (PERFORM), and an indirect influence on personal outcomes (PEROUTC), by way of performance (PERFORM). Hypothesis $\mathrm{H}_{.} \mathrm{a}$ : the factor prior experience (PRIOREXP) has a direct influence on the factor personal outcomes (PEROUTC). Hypothesis $H_{3} b$ : The factor prior experience (PRIOREXP) has a direct influence on the factor performance of the firm (PERFORM), and an indirect influence on personal outcomes (PEROUTC), by way of performance (PERFORM). Hypothesis $H_{.4} a$ : the factor relationships with agents in the environment (RELAGENV) has a direct influence on the factor personal outcomes (PEROUTC). Hypothesis H.4b: The factor relationships with agents in the environment (RELAGENV) has a direct influence on the factor performance of the firm (PERFORM), and an indirect influence on personal outcomes (PEROUTC, by way of performance (PERFORM).

Figure 2: Structural model of the worker cooperative entrepreneurship process

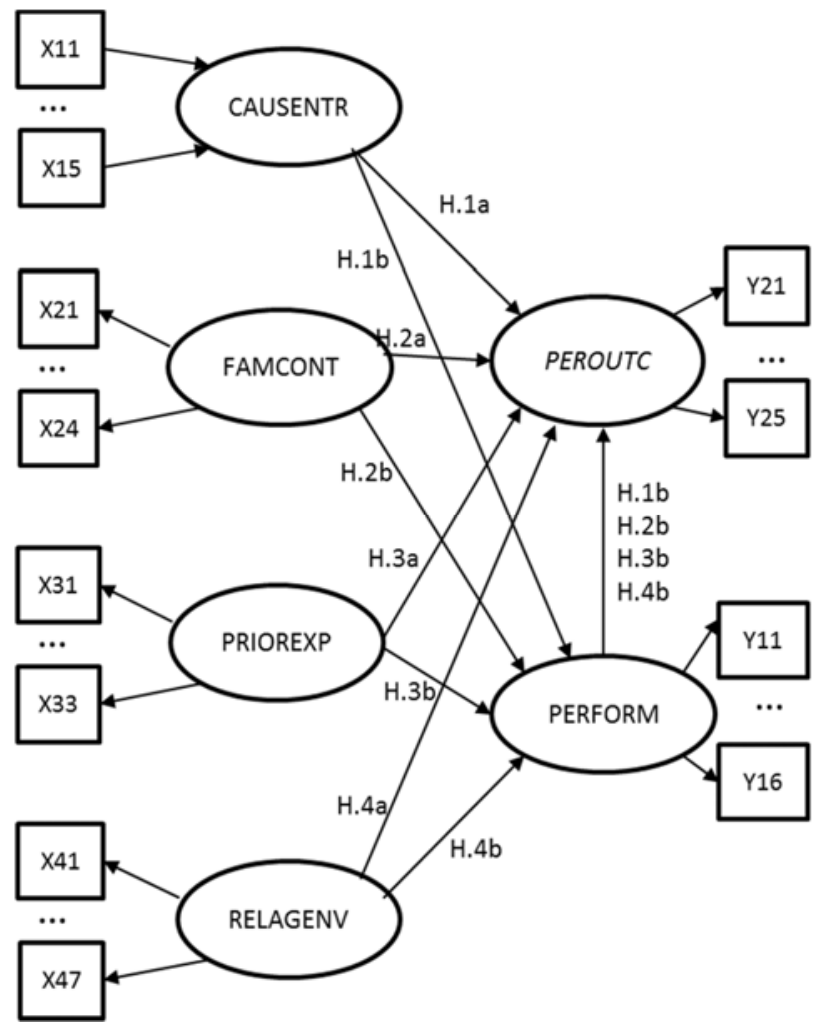

Source: compiled by author 


\section{Analysis and Discussion of Results}

\section{Evaluation of Measurement Model}

Tables 3 and 4 report the results of the assessment of the structural model's reliability and validity, at both individual item and construct level. Table 3 shows that at construct level, each of the model's factors has a high level of composite reliability, with required values in excess of 0.7 , as the items remaining after elimination are highly correlated and reliably represent each factor. This is also the case of its convergent validity, with AVE values above 0.5. The exception is the factor causes for entrepreneurship, which, as a formative construct, does not make sense in the use of these indicators, and requires a different kind of analysis. Table 4 shows the discriminant validity of the different constructs, whereby the square root of their AVE is greater than the correlations with the rest of the factors, which shows that each of the scales adequately measures its respective construct, and not anything else.

Table 3: Convergent reliability and validity of the measurement instrument

\begin{tabular}{|c|c|c|c|c|c|c|c|c|}
\hline $\begin{array}{c}\text { Latent } \\
\text { variable }\end{array}$ & Indicator & $\begin{array}{l}\text { Standardized } \\
\text { loading } \\
(\lambda)\end{array}$ & $\begin{array}{l}\text { Standardized } \\
\text { weight } \\
\text { (w) }\end{array}$ & $T$-value & $\begin{array}{l}\text { Composite } \\
\text { reliability }\end{array}$ & $\begin{array}{c}\text { AVE } \\
\text { (average } \\
\text { variance } \\
\text { extracted) }\end{array}$ & $\mathbf{R}^{2}$ & $Q^{2}$ \\
\hline CAUSENTR & $\begin{array}{l}\times 11 \\
\times 12 \\
\times 13 \\
\times 14 \\
\times 15\end{array}$ & & $\begin{array}{l}0.6681 \\
0.6876 \\
0.3052 \\
0.8930 \\
0.4255 \\
\end{array}$ & $\begin{array}{c}.3051^{\star * \star} \\
4.5165^{\star * \star} \\
1.1215 \\
4.2433^{\star * \star} \\
3.2455^{\star * \star}\end{array}$ & & & & \\
\hline FAMCONT & $\begin{array}{l}X 21 \\
\times 22 \\
\times 23\end{array}$ & $\begin{array}{l}0.9184 \\
0.8049 \\
0.8542\end{array}$ & & $\begin{array}{l}67.8186^{* * *} \\
23.0398^{* * *} \\
23.6050^{* * *}\end{array}$ & 0.8950 & 0.7403 & & \\
\hline PRIOREXP & $\begin{array}{l}X 32 \\
\times 33\end{array}$ & $\begin{array}{l}0.6754 \\
0.8255\end{array}$ & & $\begin{array}{l}6.1070^{\star * *} \\
9.8947^{\star * *}\end{array}$ & 0.7232 & 0.5688 & & \\
\hline RELAGENV & $\begin{array}{l}X 41 \\
\times 45 \\
\times 46 \\
\times 47\end{array}$ & $\begin{array}{l}0.8143 \\
0.8083 \\
0.7402 \\
0.8113\end{array}$ & & $\begin{array}{l}3.2621^{* \star *} \\
3.4467^{* * *} \\
6.3152^{\star * \star} \\
3.4306^{\star * *}\end{array}$ & 0.8721 & 0.6306 & & \\
\hline PERFORM & $\begin{array}{l}\text { Y11 } \\
\text { Y14 } \\
\text { Y15 } \\
\text { Y16 }\end{array}$ & $\begin{array}{l}0.9766 \\
0.9216 \\
0.9395 \\
0.7949\end{array}$ & & $\begin{array}{l}100.2221^{* * *} \\
60.2347^{* * *} \\
50.7471^{* * *} \\
16.7041^{* * *}\end{array}$ & 0.9508 & 0.8294 & 0.3519 & 0.2745 \\
\hline PEROUTC & $\begin{array}{l}\text { Y21 } \\
\text { Y22 } \\
\text { Y23 } \\
\text { Y24 } \\
\text { Y25 }\end{array}$ & $\begin{array}{l}0.9035 \\
0.9299 \\
0.9170 \\
0.8394 \\
0.9804\end{array}$ & & $\begin{array}{c}47.5353^{* * *} \\
83.4116^{* * *} \\
65.6093^{* * *} \\
27.5673^{* * *} \\
207.7771^{* * *}\end{array}$ & 0.9626 & 0.8375 & 0.8978 & 0.7139 \\
\hline
\end{tabular}

Table 4: Discriminant validity of the measurement instrument

\begin{tabular}{l|c|c|c|c|c|c|}
\hline $\begin{array}{l}\text { Latent } \\
\text { variable }\end{array}$ & 1 & 2 & 3 & 4 & 5 & 6 \\
\hline 1: CAUSENTR & - & & & & & \\
\hline 2: FAMCONT & - & $\mathbf{0 . 8 6 0 4}$ & & & & \\
\hline 3: PRIOREXP & - & 0.7239 & $\mathbf{0 . 7 5 4 2}$ & & & \\
\hline 4: RELAGENV & - & 0.4677 & 0.5032 & $\mathbf{0 . 7 9 4 1}$ & & \\
\hline 5: PERFORM & - & 0.4681 & 0.5223 & 0.5374 & $\mathbf{0 . 9 1 0 7}$ & \\
\hline 6: PEROUTC & - & 0.6150 & 0.5856 & 0.6557 & 0.8822 & $\mathbf{0 . 9 1 5 2}$ \\
\hline
\end{tabular}

Bottom triangle: correlations between the latent variables 
As to the eliminated items, since the standardized loading is $\lambda<0.7$, it is important to mention those related to the outcome factor PERFORM (items Y12 and Y13) that have not proven significant, and which enable the following analysis:

a) On the one hand, the uneven policy of employment growth in worker cooperatives, brought about by a legally enforced minimum number of worker-partners, and because the cooperatives ought to subsequently create jobs by admitting new partners or employees (item Y12).

b) On the other hand, the likewise uneven policy of investment, conditioned by the small size of the worker cooperatives, their difficulties in obtaining external financing, and the legal impossibility of their carrying out capital increases, among other practices (item Y13).

Unlike the other factors, CAUSENTR: causes for entrepreneurship, is a formative construct whose indicators may not be correlated, so the concepts of convergent validity or reliability do not make sense therein. What is important is that there be no multicollinearity between items, since if this were so it would be difficult to discern the individual effect of each of them on the factor. To ascertain the existence of multicollinearity, we have used the variance inflation factor (VIF), calculated using SPSS, having found that all items in the VIF construct are below the value of 5 , which denotes the absence of multicollinearity (Mason \& Perreault, 1991).

\section{Assessment of the Structural Model and Hypothesis Testing}

Table 5 reports the results of the assessment of model quality in terms of its predictive power and capacity, by way of the $R^{2}$ and $Q^{2}$ indicators. The first of these, according to the levels suggested by Chin (1998), indicates that the structural model has moderate predictive power for the factor performance $\left(R^{2}=0.3519\right)$, and strong for the factor personal outcomes $\left(R^{2}=0.8978\right)$. For its part, the positive value of $Q^{2}$ for both endogenous factors indicates that the model has predictive capacity. We test the hypotheses by way of bootstrapping, with which we obtain the Student t-value; and, alternately, by way of confidence intervals for percentiles 0.025 and 0.975 , a nonparametric technique that does not depend on any distribution. Both results are reported in Table 5.

Table 5: Structural model - hypothesis testing

\begin{tabular}{|c|c|c|c|c|c|}
\hline \multirow{2}{*}{$\begin{array}{l}\text { Hypothe } \\
\text { sis }\end{array}$} & \multirow[t]{2}{*}{ Relationship } & \multirow[t]{2}{*}{ Standardized $\beta$} & \multirow[t]{2}{*}{ T-value } & \multicolumn{2}{|c|}{ Confidence interval } \\
\hline & & & & $\begin{array}{c}\text { Percentile } \\
0.025 \\
\end{array}$ & $\begin{array}{c}\text { Percentile } \\
0.975 \\
\end{array}$ \\
\hline H.1b & CAUSENTR $\rightarrow$ PERFORM & 0.0214 & $0.1833 \mathrm{~ns}$ & -0.1883 & 0.2853 \\
\hline $\mathrm{H} .1 \mathrm{a}$ & CAUSENTR $\rightarrow$ PEROUTC & 0.1966 & $3.9766^{* * *}$ & 0.0751 & 0.2769 \\
\hline $\mathrm{H} .2 \mathrm{~b}$ & FAMCONT $\rightarrow$ PERFORM & 0.1400 & $1.3621 \mathrm{~ns}$ & -0.0659 & 0.3267 \\
\hline $\mathrm{H} .2 \mathrm{a}$ & FAMCONT $\rightarrow$ PEROUTC & 0.2331 & $4.4512^{* * *}$ & 0.1199 & 0.3328 \\
\hline H.3b & PRIOREXP $\rightarrow$ PERFORM & 0.2542 & $1.9641^{*}$ & 0.0922 & 0.5083 \\
\hline H.3a & PRIOREXP $\rightarrow$ PEROUTC & 0.0334 & $1.1278 \mathrm{~ns}$ & -0.2517 & 0.0011 \\
\hline $\mathrm{H} .4 \mathrm{~b}$ & RELAGENV $\rightarrow$ PERFORM & 0.2938 & $2.9472^{* *}$ & 0.1873 & 0.5810 \\
\hline $\mathrm{H} .4 \mathrm{a}$ & RELAGENV $\rightarrow$ PEROUTC & 0.2060 & $3.5000^{* * *}$ & 0.1333 & 0.3602 \\
\hline $\begin{array}{l}\text { H.1a } \\
\text { H.2a } \\
\text { H.3a } \\
\text { H.4a }\end{array}$ & PERFORM $\rightarrow$ PEROUTC & 0.6859 & $13.8776^{\star * *}$ & 0.5495 & 0.7455 \\
\hline
\end{tabular}


The discussion of the results is as follows:

- The factors cause for entrepreneurship and family context have a direct and very significant influence on personal outcomes ( $\beta=0.1966$ and $\beta=0.2331$ respectively), with the null hypothesis of the non-significant relationships rejected (H.1a and H.2a). Conversely, in their relationship with performance of the firm, the influence is practically non-existent in the case of CAUSENTR $(\beta=0.0214)$, or where it does exist, as in FAMCONT ( $\beta=0.1400)$, it is non-significant (hypotheses $H .1 b$ and H.2b).

- Prior experience has a heavy influence on performance $(\beta=0.2542)$, but a minimal influence on the expectations and personal outcomes of cooperative entrepreneurs $(\beta=0.0334)$. Thus, $H_{0}$ is rejected for hypothesis $H .3 a$, and accepted for hypothesis H.3b.

- Relationships with agents in the environment has a direct and significant influence on both outcome factors ( $\beta=0.2938$ and 0.2060 ), representing technical, advisory, collaboration, and exchange relationships as well as relationships with institutions. The relationships established with these agents is stable, and are aimed at improving the performance of the firm. Hence, the heavy impact on this dependent variable. Moreover, the establishment of institutional relationships undoubtedly improves the level of satisfaction and the personal expectations of the partner-workers in different ways, such as by making them feel represented, advised, supported, and even listened to by these agents - both public and private.

\section{Analysis of the Mediation Effects of Performance on Personal Outcomes}

For a detailed analysis of the mediation, we study the direct and indirect effects $\left(a^{*} b\right)$, disregarding the classic recommendation of Baron \& Kenny (1986) in which only in the case that the direct relationship between the two constructs $X$ and $Y$ (path $X-Y$ ) is significant could the mediation of another variable $Z$ be detected, as the direct effect could be influenced or even eliminated by the sample size. We report the results in line with the most accepted approach at present (Preacher \& Hayes, 2008; Hayes (2009), which recommends a mediation test focused not on the individual paths but on the term of the product $a * b$, by way of non-parametric techniques based on the use of confidence intervals for percentiles 0.025 and 0.975 , according to which when mediation exists, the interval of the effect $a * b$ should not include the value 0 .

Table 6 captures the results of the analysis of mediation between factors, which show that the factor performance has a mediation effect on the indirect relationships between the factors prior experience and relationships with agents in the environment and the factor personal outcomes, in which this mediation relationship is significant. For the other two factors, causes for entrepreneurship and family context, mediation cannot exist, since the direct relationship between these factors and performance is not significant.

Table 6: Confidence interval of the mediator effects

\begin{tabular}{l|c|c|c}
\hline Relationship & $\begin{array}{c}\text { Percentile } \\
\mathbf{0 . 0 2 5}\end{array}$ & $\begin{array}{c}\text { Percentile } \\
\mathbf{0 . 9 7 5}\end{array}$ & Observations \\
\hline CAUSENTR $\rightarrow$ PERFORM $\rightarrow$ PEROUTC & -0.1242 & 0.1775 & Not significant \\
\hline FAMCONT $\rightarrow$ PERFORM $\rightarrow$ PEROUTC & -0.0421 & 0.2165 & Not significant \\
\hline PRIOREXP $\rightarrow$ PERFORM $\rightarrow$ PEROUTC & 0.0565 & 0.3526 & \\
\hline RELAGENV $\rightarrow$ PERFORM $\rightarrow$ PEROUTC & 0.1224 & 0.3575 & \\
\hline
\end{tabular}

We performed the mediation analysis by calculating the indicator VAF (Hair et al., 2014) to quantify and typify this measurement, whereby the values of reference for this indicator are: $\mathrm{VAF}<20$ : no mediation; $20<\mathrm{VAF}<80$ : partial mediation, in which the independent 
variable still has a significant direct effect on the dependent variable; VAF>80: total mediation, where the independent variable still does not have a direct effect on the dependent variable, after the mediating variable is included in the model. Table 7 reports the results on the type of mediation and the VAF value for these indirect relationships, in which the following is notable:

- The factor performance plays a mediating role in the relationship between prior experience and personal outcomes and constitutes total mediation (VAF=0'8392), as the direct relationship between the factors prior experience and personal outcomes does not exist or is not significant.

- The factor performance of the firm exercises partial mediation in the relationship between the factor relationship with agents in the environment and the dependent factor personal outcomes. This measurement is partial, since the independent variable still has a significant direct effect on the dependent variable, confirmed with the value of $\mathrm{VAF}=0.4945$.

Table 7: Types of measurement - calculation of VAF

\begin{tabular}{l|c|c|c|c|c|c}
\hline \multicolumn{1}{c|}{ Relationship } & $\begin{array}{c}\text { Standardized } \\
\boldsymbol{\beta}\end{array}$ & $\begin{array}{c}\text { Direct effect } \\
\text { factor } \rightarrow \\
\text { PEROUTC }\end{array}$ & $\begin{array}{c}\text { Indirect effect } \\
\text { factor } \rightarrow \\
\text { PERFORM } \rightarrow \\
\text { PEROUTC }\end{array}$ & $\begin{array}{c}\text { VAF } \\
\text { Overall } \\
\text { effect } \\
\text { Variance } \\
\text { accounted } \\
\text { for }\end{array}$ & $\begin{array}{c}\text { Type of } \\
\text { measurement }\end{array}$ \\
\hline PRIOREXP $\rightarrow$ PERFORM & $0.2542^{*}$ & & & & & \\
\hline PRIOREXP $\rightarrow$ PEROUTC & 0.0334 & 0.0334 & 0.1744 & 0.2078 & 0.8392 & Total \\
\hline RELAGENV $\rightarrow$ PERFORM & $0.2938^{* *}$ & & & & & \\
\hline RELAGENV $\rightarrow$ PEROUTC & $0.2060^{* *}$ & 0.2060 & 0.2015 & 0.4075 & 0.4945 & Partial \\
\hline PERFORM $\rightarrow$ PEROUTC & $0.6859^{* *}$ & & & & \\
\hline
\end{tabular}

${ }^{* * *} p<0.001{ }^{* *} p<0.01{ }^{*} p<0.05$

\section{Analysis of the Moderation and Interaction Effects Between Factors}

We assess the moderation effect by exploring the values of $R^{2}$ in the original model and in the model with interaction, by way of the following expression: $f^{2}=\left(R^{2}\right.$ with interaction $-R^{2}$ without interaction) / 1- $R^{2}$ with interaction, where the indicator $f^{2}$ is known as the effect-size, (Cohen, 1998), with the following reference values: below 0.02, moderation does not exist; up to 0.15 , the moderation effect is weak; up to 0.35 , the effect is moderated; and thereafter, the moderation is strong or significant.

Applying the criteria $f^{2}$, we detect an interaction between PRIOREXP and RELAGENV with respect to the two dependent variables PERFORM and PEROUTC. The prior experience of the entrepreneurs acts in this case as a moderator of the relationships with agents in the environment, with values of $f^{2}=0.20$ and 0.13 , respectively, for each variable of the entrepreneurial outcome. Table 8 reports the results of the model with moderation. The $f^{2}$ values point to the existence of a weak moderation effect of $P R I O R E X P$ in the relationship between the factor RELAGENV and the dependent variable PEROUTC. This moderation effect is greater in the relationship between the predictor and the other outcome variable, PERFORM. Moreover, the value of the path- $\beta$ of the interaction and its level of significance signals and evaluates this interaction.

For the interpretation of the moderation effect, we use the Johnson-Neyman technique (Johnson \& Neyman,1936; Pothoff, 1964; Bauer \& Curran, 2005), based on simple slope tests (Cohen et al., 2003). We interpret the interactive effect using a graph (figures 3 and 4 ), showing the relationship between the predictor variable and the dependent variable 
for certain selected levels of the moderator variable (Aiken \& West, 1991; Jaccard \& Turrisi, 2003; Dawson, 2014).

Figures 3 and 4 show the slopes that allow interpretation of the interaction between the predictor variable RELAGENV and the moderator PRIOREXP, in their relationship with the dependent variables PEROUTC and PERFORM respectively. In both cases, it is possible to observe different behaviors arising from the effect produced by relationships with agents in the environment (RELAGENV) in each dependent variable, given the greater or lesser level of prior experience of the entrepreneurs (PRIOREXP), although there are nuances in each of the moderation relationships.

Table 8: Moderating effect of prior experience on relationships with agents in the environment

\begin{tabular}{l|c|c}
\hline & \multicolumn{2}{|c}{ Dependent variable } \\
\cline { 2 - 3 } & PERFORM & PEROUTC \\
\hline$\beta$ predictor: RELAGENV & 0.2236 & 0.3563 \\
\hline$\beta$ moderator: PRIOREXP & 0,2425 & 0.0358 \\
\hline$\beta$ interaction & -0.3651 & -0.2476 \\
\hline Student $t$ interaction & $3.3516^{\star * *}$ & $2.1406^{*}$ \\
\hline Value of $f^{2}$ & 0.20 & 0.13 \\
\hline & ${ }^{* * *} \mathrm{p}<0.001{ }^{* *} \mathrm{p}<0.01{ }^{*} \mathrm{p}<0.05$
\end{tabular}

In the case of low levels of prior entrepreneur experience, there is a major impact on the outcome variables due to the establishment and development of relationships with the agents in the environment, with a clearly positive slope; this indicates that the least experienced entrepreneurs concede more significance to external agents, with greater effects on entrepreneurial outcomes also recorded. Meanwhile, for the most experienced entrepreneurs, such relationships have a less pronounced effect on the variable PEROUTC with a slight positive slope (Figure 3), or even a clearly negative effect in the case of the PERFORM variable (Figure 4), implying a gradual abatement of these relationships with agents in the environment as the entrepreneurs gain experience, autonomy, and self-sufficiency.

Figure 3: Simple slope test (2-way). Dependent variable: PEROUTC

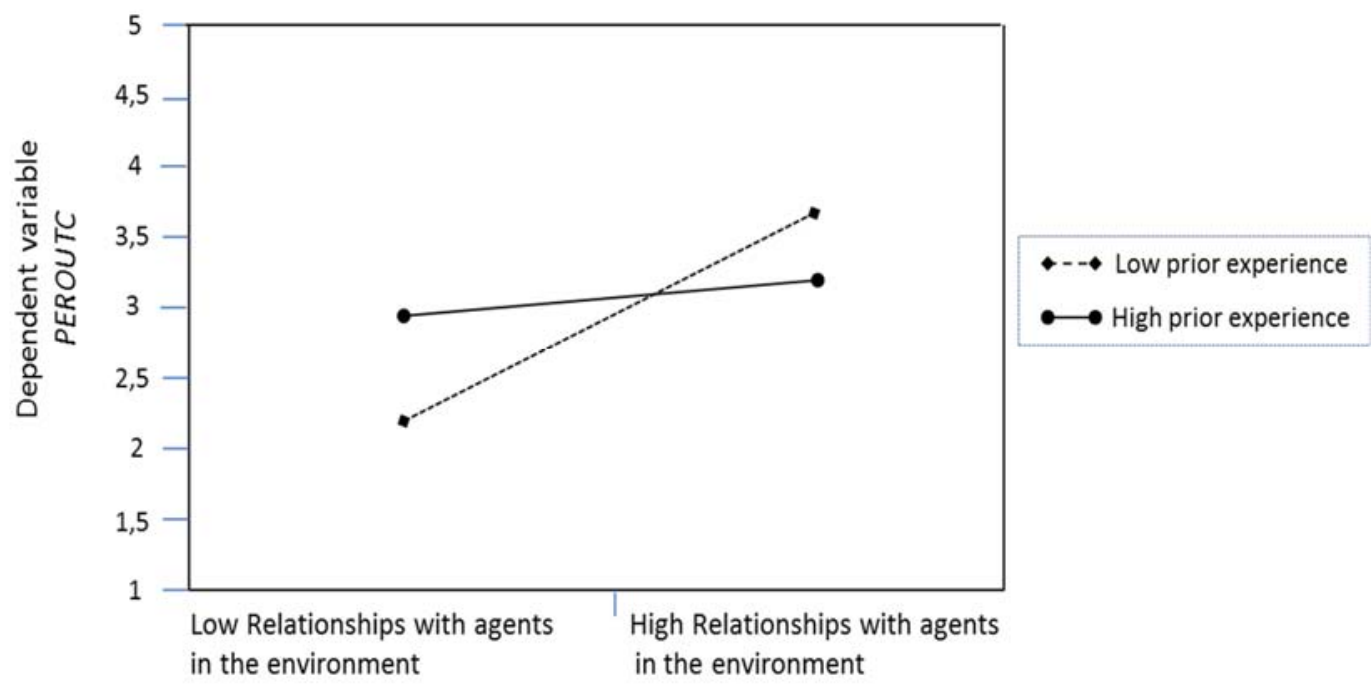

Source: compiled by author, based on Dawson (2014) 
Figure 4: Simple slope test (2-way). Dependent variable: PERFORM

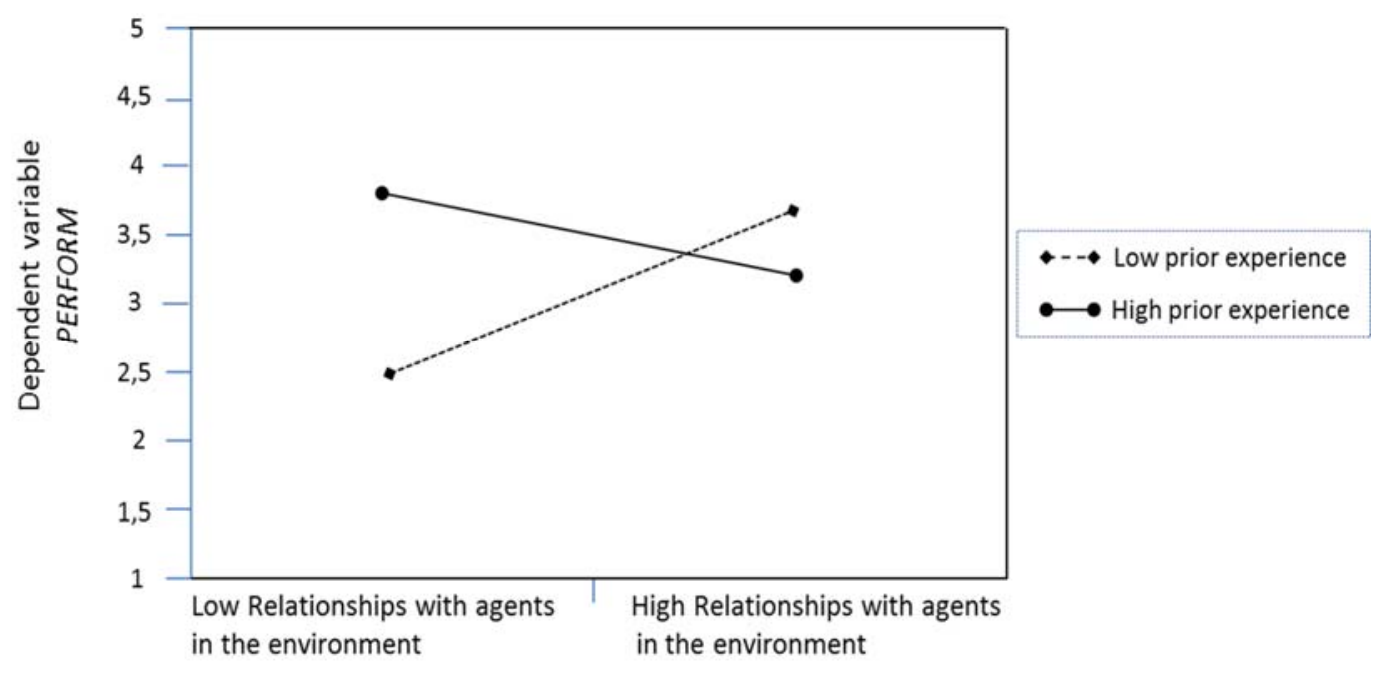

Source: compiled by author, based on Dawson (2014)

\section{Conclusions}

We seek to contribute through this study to our knowledge of the outcomes and expectations of entrepreneurs in worker cooperatives, showing that their incentives have an eminently qualitative character, and that the main purpose of their entrepreneurial activity is to achieve a form of subsistence and a measure of personal and professional development from a participative angle, without aspiring to significant material gains. This is in contrast to previous approaches that have followed the patterns of traditional entrepreneurship in which the financial perspective in the measurement of success orients all related topics.

To this end, we have studied entrepreneurial outcomes from a dual perspective: the outcomes of the firm as a product of its performance, which are shared in the case of cooperative entrepreneurs; and other, more personal outcomes associated with fulfillment of expectations and aspirations, quite apart from the firm's outcome. To this end, we selected a set of factors involved in the cooperative entrepreneurial process to study the possible impact or influence thereof on each of the factors of entrepreneurial outcome. Having analyzed the structural models, it is possible to arrive at a set of conclusions about the most important causal relationships, which can be summarized as follows:

- Certain factors representative of role theory or marginalization theory, such as the family context of cooperative entrepreneurs and the causes for entrepreneurship, have a considerable and significant influence on the personal expectations and outcomes of these entrepreneurs, although their influence is not at all reflected in the firm's material outcome - that is, in its performance.

- In turn, the entrepreneur's prior experience, a factor representative of business incubation theory, exerts a significant influence on the firm's performance, although it does not affect the other personal outcomes significantly.

- Finally, drawing from network theory, the establishment and development of relationships with certain agents in the environment, such as supplier, consulting and advisory firms, associations, and public entities, have a significant influence on both the performance of the firm and on personal expectations. 
- We have found that prior experience has an indirect effect on personal outcomes even where no direct relationship exists, due to the mediation effect it has on the outcomes of performance of the firm in which the mediation is total.

- The mediation role of performance is also observed in the relationship existing between the factor relationship with agents in the environment and personal outcomes; this relationship proves to be significant and considerable when it is direct, but is reduced when the variable performance acts as mediator, which is to say that the mediation is partial.

- Through a simple effects analysis for two ways, we have established the considerable influence of relationships with external agents in those cases in which the cooperative entrepreneurs lack prior experience. This influence is attenuated in those cases in which the entrepreneurs have more expertise and more prior experience, or are self-sufficient.

\section{Bibliography}

Amara, N., D’Este, P., Landry, R., Doloreux, D. (2016), Impacts of obstacles on innovation patterns in KIBS firms. Journal of Business Research.

Arora, A., Cohen, W. M., \& Walsh, J. P. (2016). The acquisition and commercialization of invention in American manufacturing: incidence and impact. Research Policy, 45(6), 1113-1128.

Baldwin, J., \& Lin, Z. (2002). Impediments to advanced technology adoption for Canadian manufacturers. Research policy, 31(1), 1-18.

CIS methodological, (2010). The methodological document of Community Innovation Survey 2010, Accessed in June of 2015: (https://www.ine.pt/investigadores/DOCMET_13_1_CIS_2010.pdf).

CIS, (2010). "Inquérito Comunitário à Inovação (Community Innovation Survey)", Gabinete de Planeamento, Estratégia, Avaliação e Relações internacionais, Ministério da Ciência, Tecnologia e Ensino Superior.

Clark, D. N. (2010). Innovation management in SMEs: active innovators in New Zealand. Journal of Small Business \& Entrepreneurship, 23(4), 601-619.

Cohen, W. M., \& Levinthal, D. A. (1989). Innovation and learning: the two faces of R \& D. The economic journal, 99, 569-596.

Cohen, W. M., \& Levinthal, D. A. (1990). Absorptive capacity: a new perspective on learning and innovation. Administrative science quarterly, 35(1), 128-152.

Conceição, P., \& Ávila, P. (2001). A Inovação em Portugal - II Inquérito Comunitário às Actividades de Inovação. Oeiras: Celta Editora.

D'Este, P., lammarino, S., Savona, M., \& von Tunzelmann, N. (2012). What hampers innovation? Revealed barriers versus deterring barriers. Research Policy, 41(2), 482488.

De Faria, P., Lima, F., \& Santos, R. (2010). Cooperation in innovation activities: The importance of partners. Research Policy, 39(8), 1082-1092. 
Monreal Garrido, M. (2018) Worker Cooperatives and their Entrepreneurial Process. Theoretical Foundations and Empirical Evidence from the Worker Cooperatives Established in the Valencian Community, 2008-2014. Journal of Business, Universidad del Pacifico (Lima, Peru) Vol.10(1): 2-23

Elche-Hotelano, D. (2011). Sources of knowledge, investments and appropriability as determinants of innovation: An empirical study in service firms. Innovation, 13(2), 220235.

Euchner, J. (2015). Declining barriers to innovation. Research Technology Management, November-December, 10-11.

Franco, M. J. (2003). Collaboration among SMEs as a mechanism for innovation: an empirical study. New England Journal of Entrepreneurship, 6(1), 23-32.

Freel, M. S., \& Harrison, R. T. (2006). Innovation and cooperation in the small firm sector: Evidence from 'Northern Britain'. Regional Studies, 40(4), 289-305.

Frenkel, A. (2003). Barriers and Limitations in the Development of Industrial Innovation in the Region. European Planning Studies, 11(2), 115-137.

Fukugawa, N. (2006). Determining factors in innovation of small firm networks: A case of cross industry groups in Japan. Small Business Economics, 27(2-3), 181-193.

Galia, F., \& Legros, D. (2004). Complementarities between obstacles to innovation: evidence from France. Research Policy, 33(8), 1185-1199.

Hadjimanolis, A. (1999). Barriers to innovation for SMEs in a small less developed country (Cyprus). Technovation, 19(9), 561-570.

Hidalgo, A., D’Alvano, L. (2014). Service innovation: Inward and outward related activities and cooperation model. Journal of Business Research, 67, 698-703.

Hoffman, K., Parejo, M., Bessant, J., \& Perren, L. (1998). Small firms, R\&D, technology and innovation in the UK: a literature review. Technovation,18(1), 39-55.

Hölzl, W., Janger, J. (2014). Distance to the frontier and the perception of innovation barriers across European countries. Research Policy, 43, 707-725.

Kam, W. P., Kiese, M., Singh, A., \& Wong, F. (2003). The pattern of innovation in Singapore's manufacturing sector. Singapore Management Review, 25(1), 1-34.

Kaufmann, A., \& Tödtling, F. (2001). Science-industry interaction in the process of innovation: the importance of boundary-crossing between systems. Research policy, 30(5), 791-804.

Kenny, B., \& Reedy, E. (2006). The impact of organisational culture factors on innovation levels in SMEs: An empirical investigation. Irish Journal of Management, 27(2), 119-142.

Lewandowska, M. (2014). Innovation barriers and international competitiveness of enterprises from Polish food processing industry. Research Results. ACTA Scientiarum Polonorum Oeconomia, 13(14), 103-113.

Madrid-Guijarro, A., Garcia, D., \& Van Auken, H. (2009). Barriers to innovation among Spanish

Marques, C., \& Monteiro-Barata, J. (2005). Determinantes de inovação e desempenho económico - financeiro: Ensaio para a Indústria Transformadora Portuguesa. In 4th 
Monreal Garrido, M. (2018) Worker Cooperatives and their Entrepreneurial Process. Theoretical Foundations and Empirical Evidence from the Worker Cooperatives Established in the Valencian Community, 2008-2014. Journal of Business, Universidad del Pacifico (Lima, Peru) Vol.10(1): 2-23

International Meeting of the Iberoamerican Academy of Management, Lisboa, Portugal, 8 a 11 de Dezembro, 2005. Faculdade de Economia: Universidade Nova de Lisboa.

Marques, C., \& Monteiro-Barata, J. (2006). Determinants of the innovation process: An empirical test for the Portuguese manufacturing industry. Management Research: Journal of the Iberoamerican Academy of Management, 4(2), 113-126.

Meijer, A. (2015). E-governance innovation: Barriers and strategies.Government Information Quarterly, 32(2), 198-206.

Mention, A. L. (2011). Co-operation and co-opetition as open innovation practices in the service sector: which influence on innovation novelty? Technovation, 31(1), 44-53.

Najda-Janoszka, M., \& Kopera, S. (2014). Exploring barriers to innovation in tourism industry-The case of southern region of Poland. Procedia-Social and Behavioral Sciences, 110, 190-201.

Nunes, A. (2008). Barreiras à capacidade inovadora empresarial: estudo nas empresas portuguesas, Dissertação de Mestrado, Universidade da Beira Interior, Covilhã

Nunes, A., \& Silva, M. J. (2010). Constrangimentos Económicos e de Mercado na Capacidade Inovadora das Empresas Portuguesas: Evidências Empíricas ao Nível da Inovação no Processo. In Proceedings of XX Luso - Spanish Conference on Management, 4-5 February, 2010. Instituto Politécnico de Setúbal, Portugal.

Nunes, S., Carvalho, L., \& Costa, T. (2013). Cooperation for innovation: evidence from southern European countries. International Journal of Innovation and Regional Development 7, 5(2), 226-241.

OCDE (2005). OSLO Manual: Proposed Guidelines for Collecting and Interpreting Technological Innovation Data (3rd ed.). Paris: OECD Publishing. doi: http://dx.doi.org/10.1787/9789264013100-en.

Parrilli, M. D., \& Heras, H. A. (2016). STI and DUI innovation modes: Scientifictechnological and context-specific nuances. Research Policy,45(4), 747-756.

Perel, M. (2002). Corporate courage: Breaking the barrier to innovation. Research Technology Management, May-June, 9-17.

Porter, M. E. (1990). The Competitive Advantage of Nations. New York: Macmillan.

Romijn, H., \& Albaladejo, M. (2002). Determinants of innovation capability in small electronics and software firms in southeast England. Research policy, 31(7), 1053-1067.

Saatcioglu, O., Ozmen, O. (2010). Analyzing the barriers encountered in innovation process through interpretative structural modelling: evidence from Turkey. Yonetim Ve Ekonomi, 17(2), 207-225.

Saatcioglu, O., Ozmen, O. (2010). Analyzing the barriers encountered in innovation process through interpretative structural modelling: evidence from Turkey. Yonetim Ve Ekonomi, 17(2), 207-225.

Sawang, S., \& Matthews, J. H. (2010). Positive relationships among collaboration for innovation, past innovation abandonment and future product introduction in 
Monreal Garrido, M. (2018) Worker Cooperatives and their Entrepreneurial Process. Theoretical Foundations and Empirical Evidence from the Worker Cooperatives Established in the Valencian Community, 2008-2014. Journal of Business, Universidad del Pacifico (Lima, Peru) Vol.10(1): 2-23

manufacturing SMEs. Interdisciplinary Journal of Contemporary Research in Business, 2(6), 106-117.

Segarra-Blasco, A., Garcia-Quevedo, J., \& Teruel-Carrizosa, M. (2008). Barriers to innovation and public policy in Catalonia. International entrepreneurship and management journal, 4(4), 431-451.

Silva, M. J., Leitão, J., \& Raposo, M. (2008). Barriers to innovation faced by manufacturing firms in Portugal: how to overcome it for fostering business excellence?. International Journal of Business Excellence, 1(1-2), 92-105.

Silva, M. J., Campos, M. I. M., \& Nunes, A. (2009). Barriers to Innovation and Entrepreneurial Innovation Capability: Empirical Evidence From Portuguese CIS Data at the Product Innovation Level. In ECEI2009-4th European conference on entrepreneurship and innovation: ECEI2009 (p. 440). Academic Conferences Limited.

Simões, V.C. (1996). Inovação e Gestão em PME Industriais Portugueses: Relatório Técnico. Lisboa: GEP - Gabinete de Estudos e Planeamento do Ministério da Economia. Song, C., \& Oh, W. (2015). Determinants of innovation in energy intensive industry and implications for energy policy. Energy Policy, 81, 122-130.

Thakur, R., Hale, D. (2013). Service innovation: A comparative study of U.S. and Indian service firms. Journal of Business Research, 66, 1108-1123.

Tourigny, D., \& Le, C. D. (2004). Impediments to innovation faced by Canadian manufacturing firms. Economics of Innovation and New Technology, 13(3), 217-250.

Ussman, A., Almeida, A., Ferreira, J., Mendes, L., \& Franco, M. (2001). SMEs and innovation: Perceived barriers and behavioural patterns. The International Journal of Entrepreneurship and Innovation, 2(2), 111-118.

Varis, M., \& Littunen, H. (2010). Types of innovation, sources of information and performance in entrepreneurial SMEs. European Journal of Innovation Management, 13(2), 128-154.

Vermeulen, P. A. (2005). Uncovering Barriers to Complex Incremental Product Innovation in Small and Medium-Sized Financial Services Firms. Journal of Small Business Management, 43(4), 432-452.

Xie, X. M., Zeng, S. X., \& Tam, C. M. (2010). Overcoming barriers to innovation in SMEs in China: A perspective based cooperation network. Innovation, 12(3), 298-310.

Yu, X., Yan, J., \& Assimakopoulos, D. (2015). Case analysis of imitative innovation in Chinese manufacturing SMEs: Products, features, barriers and competences for transition. International Journal of Information Management, 35(4), 520-525.

Zwick, T. (2002). Employee resistance against innovations. International Journal of Manpower, 23(6), 542-552. 